Was macht die Digitalisierung mit den Hochschulen? 

Marko Demantowsky, Gerhard Lauer,

Robin Schmidt, Bert te Wildt (Hrsg.)

\title{
Was macht die Digitalisierung mit den Hochschulen?
}

Einwürfe und Provokationen

\author{
De Gruyter \\ Oldenbourg
}


Wir danken der Gerda Henkel Stiftung (Düsseldorf), dem Stifterverband für die deutsche Wissenschaft (Essen), der Artemed-Klinikgruppe (Tutzing) und der Pädagogischen Hochschule FHNW (Basel/Brugg-Windisch) für die großzügige Finanzierung der Dießener Klausur Mensch|Maschine|Zukunft 2019 und damit auch für die Ermöglichung dieses Buches.

\title{
(cc) BY-NC-ND
}

Dieses Werk ist lizenziert unter der Creative Commons Attribution-NonCommercialNoDerivatives 4.0 International-Lizenz. Weitere Informationen finden Sie unter http://creativecommons.org/licenses/by-nc-nd/4.0/.

\author{
ISBN 978-3-11-067322-7 \\ e-ISBN (PDF) 978-3-11-067326-5 \\ e-ISBN (EPUB) 978-3-11-067331-9 \\ DOI https://doi.org/10.1515/9783110673265
}

Library of Congress Control Number: 2020908022

Bibliografische Information der Deutschen Nationalbibliothek

Die Deutsche Nationalbibliothek verzeichnet diese Publikation in der Deutschen

Nationalbibliografie; detaillierte bibliografische Daten sind im Internet über http://dnb.dnb.de abrufbar.

(C) 2020 Marko Demantkowsky, Gerhard Lauer, Robin Schmidt, Bert te Wildt, publiziert von Walter de Gruyter GmbH, Berlin/Boston

Dieses Buch ist als Open-Access-Publikation verfügbar über www.degruyter.com.

Umschlagabbildung: Screenshot aus «Lucid Trips» (C) Sara Lisa Vogl

Druck und buchbinderische Verarbeitung: CPI books GmbH, Leck

www.degruyter.com 